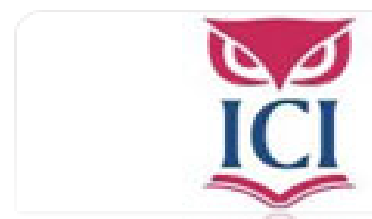

IUS. Revista del Instituto de Ciencias Jurídicas de Puebla A.C.

ISSN: 1870-2147

revista.ius@hotmail.com

Instituto de Ciencias Jurídicas de Puebla A. C.

México

Soto Senra, Georgina Marcia

La adopción internacional, pertinencia y peligros

IUS. Revista del Instituto de Ciencias Jurídicas de Puebla A.C., núm. 20, 2007, pp. 126-138 Instituto de Ciencias Jurídicas de Puebla A. C.

Puebla, México 


\title{
LA ADOPCIÓN INTERNACIONAL, PERTINENCIA Y PELIGROS
}

\author{
Georgina Marcia Soto Senra*
}

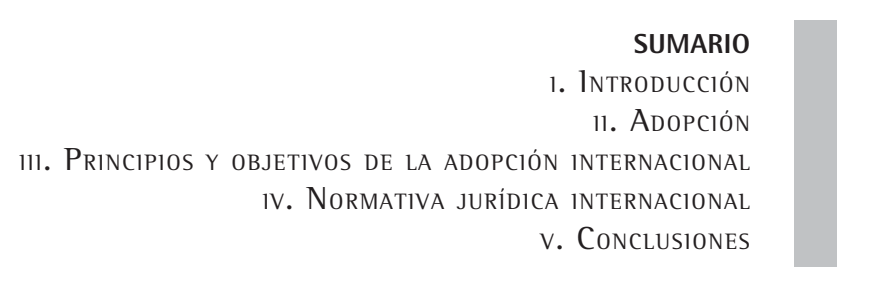

\section{RESUMEN}

El presente artículo aborda la institución de la adopción, destacando cómo la misma es superada desde su visión tradicional al trascender las fronteras nacionales. Nacida como paliativo a parejas infértiles o como sustitutivo de la natural descendencia que garantizara la estirpe familiar y la continuidad del patrimonio de la familia se convierte además en una vía para posibilitar al menor desamparado el contexto familiar que permita su desarrollo como ser humano. La comunidad jurídica internacional ha dirigido empeños legislativos encaminados a establecer normas que garanticen el principio rector de la protección a los derechos humanos de niños/as: la observancia estricta del interés superior del niño o niña en todos los asuntos relacionados con sus derechos subjetivos.

\section{ABSTRACT}

The present article approaches the institution of the adoption, highlighting as the same one is overcome from its traditional vision when transcending the national frontiers. Born as palliative to couples that cannot have children or as substitute of the natural descendant that it guaranteed the family stock and the continuity of the patrimony of the family also becomes a road to facilitate the abandoned minor the family context that allows its development as human being. The international artificial community has directed legislative zeals guided norms that guarantee the principle rector from the protection to the human rights of children and girls to settle down: the strict observance of the boy's superior interest or girl in all the matters related with their subjective rights.

* Maestra en derecho y especialista en derecho civil. Profesora de la Universidad de Camagüey, Cuba. 


\section{INTRODUCCIÓN}

El siglo XXI abrió sus puertas para un derecho de familia motivado por los trascendentales descubrimientos científicos y técnicos que han revolucionado las bases biológicas de carácter natural sobre las que se erigieron tradicionalmente las relaciones familiares. Nuevos retos, nuevos horizontes en el quehacer jurídico para los estudiosos del derecho imponen la profundización obligada de sus instituciones jurídicas. Sin lugar a dudas, una de estas instituciones es la adopción.

Hoy la realidad familiar se ve matizada por las influencias globalizadoras. Las funciones de la familia como célula básica de una sociedad reciben su influjo. En las distintas instituciones del derecho familiar, la tendencia hacia la internacionalización de sus relaciones se vislumbra como aspecto de especial atención.

En el contexto de las relaciones jurídicas familiares confluyen intereses patrimoniales y personales que imprimen un sello particular a aquellas relaciones para las que muchos defienden su independencia sustantiva y procesal del derecho civil. Los argumentos sobre los que se edifican estas posiciones se centran en la naturaleza jurídica misma del derecho familiar.

La adopción es una institución conocida en el derecho de familia desde la antigüedad. Hoy la tendencia mayoritaria apunta a entenderla como la relación parental, no natural entre dos personas que aunque no están unidas por vínculos consanguíneos existe entre ellas una relación igual a la existente entre padres e hijos naturales, de manera que se asumen los mismos efectos jurídicos tal y como si la relación filiatoria se hubiere producido de forma natural o artificial. ${ }^{1}$

Díez Picazo y Gullón Ballesteros (1983) afirman: "Se trata de una institución que en los tiempos modernos ha ido adquiriendo un nuevo auge y una gran vitalidad, que han dado lugar a reiteradas y profundas reformas en la legislación. La adopción suscita el interés público, que encuentra a través de ella un cauce para realizar aspiraciones y deseos de los matrimonios sin hijos, y de amparo de los niños abandonados o recogidos en establecimientos benéficos." ${ }^{2}$

\footnotetext{
${ }^{1}$ La filiación en la contemporaneidad y para las ciencias jurídicas como resultado de descubrimientos científicos y técnicos sucedidos en la genética, se obtiene de forma artificial a partir de las técnicas de reproducción asistida, bien sea de forma homóloga o heteróloga.

${ }^{2}$ Luis Díez Picazo y Antonio Gullón Ballesteros, Sistema de derecho civil, Vol. 4. Derecho de familia. Derecho de sucesiones, 1983, p. 302.
} 
Conocida en sus inicios como paliativo a la infertilidad de la pareja, o como vía de garantía para la continuidad de la estirpe familiar y la subsistencia del patrimonio familiar, trasciende ya los marcos nacionales y se pronuncia sobre los objetivos que ampara la normativa jurídica internacional. La Convención de los Derechos del Niño de 1989 y el Convenio Internacional de La Haya, relativo a la protección del niño y a la cooperación en materia de adopción internacional adoptado en 1993, han permitido a los países trazar pautas comunes en pos del cumplimiento y materialización a nivel internacional del interés superior del niño/a.

\section{AdOPCIÓN}

La adopción dentro de las instituciones del derecho familiar es una de las más antiguas. Surge con la concepción religioso-jurídica de la familia gentilicia y patriarcal civilizada de Caldea, Babilonia, Egipto y la India. La Biblia alude a la institución de la adopción en dos conocidas oportunidades: cuando Jacob tiene como hijos a los de José que habían nacido en Egipto y dijo: "Y ahora tus dos hijos Efraín y Manasés que te nacieron en la tierra de Egipto míos son...”; y cuando José es criado por la princesa egipcia, hija del faraón, quien lo prohijó y puso por nombre Moisés.

En Grecia y Roma tuvo de igual manera un sentido político-religioso, debido al significado que en esa época se le otorgó al culto familiar y a su continuidad.

Así, en la antigüedad la adopción se constituyó como el medio dado por la religión y las leyes a aquellos que estaban desprovistos de herederos para garantizar la continuación de la estirpe y la supervivencia del culto doméstico y cuya extinción significaba una catástrofe familiar que era necesario evitar.

En Roma se solidificó dentro de la organización de la familia patriarcal romana. El desarrollo económico en Roma potenciaría el surgimiento de nuevos intereses vinculados con la adopción, no sólo por parte de los adoptantes, sino también de los adoptados. Muchos encontraron en esta institución la forma de ingresar a una clase social determinada para luego escalar hacia determinadas posiciones con un matrimonio ventajoso que les permitiera luego magistraturas. Entre los numerosos ejemplos que podemos citar se encuentra la costumbre extendida entre los patricios de renunciar a su condición e ingresar en la plebe (transitio ad plebem) para

${ }^{3}$ En el Génesis. 
poder aspirar al tribunado. Augusto, por ejemplo, había sido adoptado por la familia de los Julios, a la que pertenecía César, de quien sería sucesor; la historia se repite entre Augusto y Tiberio (42 a.n.e-37 n.e). Nerón (3768 n.e) ascendería al trono imperial por haber sido adoptado por Claudio (10-54 n.e).

Los romanos desarrollaron primero la figura de la adrogatio (arrogación), que consistía en la incorporación a la familia de una persona sui iuris, la que pasando a ser alieni iuris quedaba sometida a la patria potestad del arrogante, un tanto con el objetivo evidente de asegurar fuerza de trabajo y sucesión en el patrimonio y el poder político al pater familia arrogante, logrando además adquirir derechos sucesorios en la herencia de la persona que lo arrogaba.

Menos antigua fue la adoptio, que consistió en la incorporación de un alieni iuris a otra familia. Se lograba inicialmente mediante tres emancipaciones o ventas solemnes (mancipatio) del alienis iuris y una posterior cesión en derecho (cesio in jure) del mismo a su adoptante a fin de que, por las primeras saliera de la patria potestad de su pater familia y, por la segunda quedara sometido a la del adoptante. Justiniano también simplificó el procedimiento al disponer que bastara la aprobación de un magistrado (imperius magistratus), es decir mediante una comparecencia o juicio y mediante la firma de un protocolo judicial, en el que se recogía la conformidad del adoptante y del adoptado.

La adopción podía ser plena o perfecta si el adoptado era descendiente del adoptante, con lo que quedaba sometido a su patria potestad; y menos plena o imperfecta si el adoptado era colateral del adoptante o un extraño; entonces el adoptante no adquiría la patria potestad sobre el adoptado, que quedaba bajo la patria potestad de su padre original, aunque adquiría los demás derechos y obligaciones parentales con respecto al adoptante y su familia.

Podemos decir entonces, que esta institución en Roma estuvo basada en los hechos de:

- Tener herederos para perpetuar la continuidad familiar y preservar la herencia familiar.

- El deseo de pasar de una clase social a otra para ocupar magistraturas privilegiadas.

- El hecho de legitimar sin escándalo social a un hijo natural.

- Hacer entrar a la familia a descendientes por la línea femenina. 
Durante la etapa del Imperio en Roma, la adopción fue cayendo en desuso. Los pueblos germanos que invadieron y ocuparon los territorios romanos o que formaron parte de sus provincias, no conocieron a profundidad la adopción como institución con efectos jurídicos como los reguló el romano.

En la Edad Media la institución adoptiva fue prácticamente inaplicable, ya que se redujo la posibilidad de heredar del adoptado cuando el causante tenía descendientes legítimos. Se retoma en la historia del derecho con posterioridad, y ya entre los franceses la adopción se presenta con los caracteres tomados tanto del derecho romano como del germánico, presenciándose ya de nuevo con cierta fuerza la institución que había caído en desuso, y para la elaboración del Código Napoleónico se logran agrupar en un solo cuerpo legal las diversas disposiciones y costumbres vigentes relativas a su esencia. La finalidad, sin embargo, no se centró en el criterio moderno de protección a la infancia ni en el romano de continuidad del culto, sino más bien en la solución biológica que como recurso ofrecían las leyes para consolar a los individuos sin hijos.

En España la adopción como institución no fue reconocida en el Fuero Viejo, ni en el Fuero Juzgo, ni en los fueros municipales. Sólo aparecen en las Leyes del Toro, la Novísima Recopilación, en el Fuero Real, donde ya resulta mencionada y en las Partidas, en la que se le da el tratamiento de verdadera institución jurídica.

En el derecho español, especialmente en las Partidas, se presentó la adopción con las mismas características que la individualizaron los romanos, con excepción del carácter religioso que primó en sus orígenes históricos.

El derecho canónico o eclesiástico que rigió paralelamente con estas legislaciones, respetó la institucionalización civil a la cual se acogió, al proclamar que la adopción tendría como objeto la protección de los hijos expósitos o desamparados.

Las influencias del sistema romano, francés y germánico en las legislaciones latinoamericanas se evidencian en los códigos de la época. De esta manera han llegado a nuestros días formulaciones legislativas similares en la mayoría de las legislaciones del área, ${ }^{4}$ y la tendencia a aceptar, en muchas ya reformuladas, la pertinencia en virtud de sus efectos absolutos, de la adopción plena, aquella en la que se constituyen nuevas relaciones paternas filiales una vez autorizada la adopción con la familia adoptiva.

${ }^{4}$ Código Civil del Distrito Federal, México. 
Toda regla admitiendo excepciones permite en algunos países la posibilidad de mantener relaciones con la familia natural materna o paterna en los casos, por ejemplo, que se trate de la adopción de uno de los hijos del adoptante en caso de adopción entre cónyuges. ${ }^{5}$

La adopción creadora de un nuevo status filiae y familiae se presenta como un acto irrevocable. La frase del autor español Albaladejo es convincente en ello. Ha dicho: "La única adopción de hoy y su efecto básico de sacar legalmente al adoptado de su familia anterior e integrarlo en la del adoptante como un acto solemne que da al adoptante (o adoptantes) como hijo, al adoptado, creándose así un vínculo de parentesco puramente jurídico pero por disposición legal, con igual fuerza y efecto que si fuera de sangre..."

\section{Principios y objetivos de la adopción internacional}

El contexto mundial actual globalizado ha incidido en la internacionalización de las relaciones sociales en general, y de las relaciones jurídicas en particular. No escapan a sus efectos las relaciones jurídicas de tipo familiares que han sido determinantes hoy en los fenómenos de la multiculturalidad, donde la fusión de familias con miembros de distintas nacionalidades ha contribuido a variar conceptos clásicos conocidos en las ciencias sociales, en tanto, la familia constituye por sus funciones la célula básica de la sociedad. La adopción internacional se erige así como una de las consecuencias de la globalización en las relaciones familiares de nuestros días, convirtiéndose en una práctica generalizada en la mayoría de los países.

En su génesis la variante internacional de la adopción se encuentra en las respuestas de la comunidad internacional a los fenómenos ocasionados por las nefastas guerras mundiales. Fue concebida principalmente como el hallazgo humanitario a las situaciones de emergencia y crisis de los niños/ as que se encontraron de momento ante realidades de desamparo total, al perder muchos de ellos a sus padres o a la totalidad de sus familiares.

Si se habla de su pertinencia actual, no sólo se identifica la posibilidad para las personas infértiles, o la garantía para niños/as de encontrarse ante situaciones de desamparo familiar de los que muchos padecen el hogar idóneo para su desarrollo personal en el contexto de una familia.

${ }^{5}$ Código Civil español, artículo 178.

${ }^{6}$ M. Albaladejo, Curso de derecho civil. Derecho de familia, 1989, p. 275. 
Mundialmente hoy, las tasas de natalidad son excesivas en varios países subdesarrollados, principalmente en familias donde es imposible regular el control de la natalidad por los niveles de pobreza y por los escasos recursos monetarios para acceder a los servicios de salud, mientras que en algunos países más desarrollados se encuentran deprimidas las tasas de fecundidad y natalidad.

Las causas que en los inicios motivaron las adopciones internacionales han sido modificadas en la actualidad. El comercio de menores con disímiles fines constituye una preocupación para los nuevos hechos que hoy día pueden determinarla.

Existe la posibilidad de lucrar alrededor de actos como el tráfico y la trata de menores, la explotación sexual, y otras formas lacerantes que afectan la dignidad misma del niño/a como personas. No se pretende ejemplificar con estadísticas que a diario varían de una realidad inevitable que nos llegan por los canales de información actualizados para demostrar la obligada reflexión que debe significar el hecho real de las adopciones internacionales como la vía que puede permitir tales prácticas. Las cifras son alarmantes para quienes propugnan y defienden la humana idea de que nada es más importante que un niño/a, y para quienes es imperativo de primer orden la defensa en todo momento del interés superior del niño/a.

\section{Normativa JURíDICA INTERNACIONAL}

El derecho internacional ha estado a la vanguardia en las respuestas que ha dado el ordenamiento jurídico en su protección a los derechos humanos de niños/as, adoptando normas jurídicas tendientes a trazar normas de conducta universales para facilitar la protección de los derechos subjetivos de las personas que deben su existencia dentro de esta categoría, a un concepto hoy denominado de niño/a.

La Declaración de los Derechos del Niño en el año 1959 constituyó el precedente más directo de la Convención de los Derechos del Niño en el año 1989. Se adopta por la Asamblea General de las Naciones Unidas el 20 de noviembre del año 1989. En el ámbito jurídico su significación pudiera abarcar múltiples interpretaciones, pero es indudable que la aparición de este documento jurídico internacional revolucionó la visión hasta entonces existente desde su perspectiva jurídica del niño/a como persona y como sujeto de derechos, comenzando a desarrollarse la doctrina de la protección integral sobre el principio del "interés superior del niño", que- 
dando superada la doctrina de la protección irregular presente hasta ese momento.

El artículo 21 del precitado texto legislativo, precisa: "Los estados que reconocen y/o permiten el sistema de adopción, cuidarán de que el interés superior del niño sea la consideración primordial..."

A partir de este instante y desde la década de los ochenta del siglo $\mathrm{xx}$ los esfuerzos por contar con normas y acuerdos internacionales en materia de adopción internacional fueron intensos, hasta que definitivamente fructificaron y se exhiben en la actualidad avances legislativos importantes y significativos en algunos países.

El 29 de mayo de 1993 fue suscrito por 57 países el Convenio de La Haya relativo a la protección del niño/a en la cooperación internacional en materia de adopción internacional, representando para los niños/as, las familias y los estados un desafío de enorme trascendencia su aplicación.

Quedó introducido desde su entrada en vigor el término "adopción internacional" para identificar a la adopción de menores en la cual los adoptantes y adoptados son de nacionalidad o domicilios diferentes, asumiéndose para el adoptante la filiación adoptiva como consecuencia de la filiación ficticia creada y protegida por la cual se derivan relaciones paterno-filiares (entre adoptante y adoptado) semejantes a las derivadas de la filiación natural.

En la generalidad de los casos se aconseja aceptar en la adopción internacional la forma plena, pues la adopción en su forma semiplena provoca la subsistencia de vínculos legales con la familia de sangre y por consiguiente pueden existir en conflicto determinados efectos patrimoniales derivados de los efectos personales nacidos como consecuencia de la adopción. Además, irremediablemente la adopción internacional provoca un cambio en sus costumbres, cultura, idioma, religión, y en sentido general se modifican los aspectos relativos a su identidad personal de origen ante el hecho cierto del alejamiento de sus raíces naturales, las que se mantienen, pero por el mero hecho del nacimiento, son por fuerza modificadas al cambiar el entorno real en el que se desarrolla el menor. No obstante el niño/a tiene derechos en virtud de las disposiciones establecidas en la Convención de los Derechos del Niño, para los estados partes en ella, a tenor de lo establecido en su articulado, los que deben comprometerse a respetar el derecho del niño a preservar su identidad.

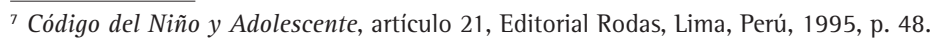


Obsérvese la propia norma que se expresa en este sentido, cuando señala:

El reconocimiento de la adopción comporta el reconocimiento:

a) Del vínculo de filiación entre el niño y sus padres adoptivos.

b) De la responsabilidad de los padres adoptivos respecto al hijo.

c) De la ruptura del vínculo de filiación preexistente entre el niño y su madre y su padre si la adopción produce este efecto en el Estado contratante en el que ha tenido lugar. ${ }^{8}$

Un significativo precepto contenido en la Convención sobre los Derechos del Niño, cuando se refiere a la adopción, señala el artículo 21: "Los estados que reconocen y/o permiten el sistema de adopción, cuidarán de que el interés superior del niño sea la consideración primordial...”; y añade en su apartado e): "Promoverán, cuando corresponda, los objetivos del presente artículo mediante la concertación de arreglos o acuerdos bilaterales o multilaterales y se esforzarán dentro de este marco, por garantizar que la colocación del niño en otro país se efectúe por medio de las autoridades u organismos competentes."

Así, la convención de 1993, elaborada bajo los auspicios de la Conferencia de La Haya, adopta el documento jurídico internacional encaminado a la protección del niño y a la cooperación en materia de adopción internacional, pretendiendo establecer un equilibrio entre la salvaguarda de la vida cultural del menor, manteniendo su propia personalidad, y la necesidad de su inserción en un hogar. Los estados signatarios argumentaron la necesidad de crear un marco jurídico, para asegurar el respeto a los derechos fundamentales y la toma de medidas en cada país que garantizaran que las adopciones internacionales se realizaran teniendo en cuenta, en primer lugar, el interés superior del niño.

La base y eje central del actual Convenio de La Haya, es la cooperación internacional misma en materia de adopción, con el fin de luchar contra el tráfico que se desarrollaba alrededor de las adopciones internacionales. Se centra en principios tales como:

- Entender la adopción como una de las formas de protección a la infancia.

${ }^{8}$ Cfr. Convención de La Haya de 1993, Art. 26.

${ }^{9}$ Cfr. Convención de los Derechos del Niño de 1989, Art. 21. 
- Comprender el carácter subsidiario de la adopción internacional, no necesariamente la única opción ante la infertilidad de una pareja.

- La imperativa necesidad de suscitar una cooperación internacional entre los estados para intentar disminuir o, por lo menos, combatir las adopciones clandestinas.

Como aspectos relevantes de este cuerpo legal, deben ser destacadas en la adopción las exigencias personales a las partes involucradas con la adopción internacional, resumidas en:

- Garantías en cuanto a los adoptantes interesados: Este convenio contempla que la autoridad competente valore y certifique la idoneidad de los solicitantes para la adopción, así como su preparación para la misma.

- Garantías para los adoptados: Las autoridades competentes aseguran la adaptabilidad del niño, garantizando que se han dado los consentimientos requeridos y controlando que no ha existido pago indebido.

A través de esta convención, se implementa una serie de medidas que deben observarse para el buen fin de las adopciones internacionales. Se destacan las siguientes:

- El reconocimiento y la proyección para el desarrollo armónico de la personalidad del niño, el cual debe crecer en un medio familiar que propicie un clima de felicidad, amor y comprensión.

- Se emplaza a las autoridades competentes a tomar medidas adecuadas que permitan mantener al niño en su familia de origen.

- Se reconoce que la adopción internacional puede presentar la ventaja de dar una familia permanente a un niño que no puede encontrar una familia adecuada en su Estado de origen.

- Se sugiere que se incrementen las medidas que garanticen que las adopciones internacionales tengan en consideración el interés superior del niño y el respeto a sus derechos fundamentales, así como las encaminadas a prevenir la sustracción, la venta o el tráfico de menores. 
A raíz de la firma o adhesión a la Convención de La Haya, los estados han ido acordando convenios bilaterales garantes de los principios y formulaciones adoptados desde que se convierten en signatarios de la convención de 1993. El reto mayor ha de consistir en la implementación de las garantías necesarias y suficientes por parte de los estados encaminadas a garantizar los principios informadores en la plena protección integral del menor con la observancia estricta en todo momento del interés superior del niño como paradigma de garantía de los derechos humanos de niños y niñas.

\section{v. Conclusiones}

Como institución del derecho familiar, la adopción supera hoy los cánones tradicionales conocidos históricamente para erigirse en la actualidad como una de las manifestaciones más evidentes de la influencia de las tendencias globalizadoras en los marcos del derecho.

La Convención de los Derechos del Niño de 1989 y la Convención en Materia de Protección al menor en materia de adopción internacional de 1993 se han convertido en documentos de gran significación jurídica, como máximos exponentes del valor de la justicia en el contexto del derecho internacional moderno, y símbolos además de la preocupación constante de la comunidad jurídica internacional por la protección especial de los derechos humanos del niño/a.

Corresponde a los estados partes de este importante documento internacional hacer realidad la protección real de los principios enunciados en él, y garantizar los mecanismos legales que propendan al logro efectivo de proteger el interés superior del niño/a.

\section{Referencias}

Albadalejo, Manuel, Curso de derecho civil, Librería Bosch, Barcelona, 1982.

Albañez, Teresa, "Derechos humanos: el caso de los niños", en Revista de la CEPAL, Santiago de Chile, diciembre de 1995.

Blumkim, Silvia Beatriz, "La sustracción internacional de menores”, en Revista del Colegio de Abogados de la Ciudad de Buenos Aires, Buenos Aires, julio de 1995.

Boletín Mexicano de Derecho Comparado, Nueva Serie, Año xxxviI, No. 110, Instituto de Investigaciones Jurídicas, Universidad Nacional Autónoma de México, México, mayo-agosto de 2004. 
Calua Ruiz, María Elena, "La patria potestad y su incidencia en el derecho comparado", v Convención Latinoamericana de Derecho "El derecho en el nuevo contexto latinoamericano”, Bolivia, noviembre de 2003.

Calvo García, Manuel, "La protección del menor y sus derechos”, en Derechos y Libertades, 2, Madrid, octubre-marzo, 1993-1994.

Castán Tobeñas, José, Derecho civil español, común y foral, Editorial Reus, Madrid, 1985.

Camus, Curso de derecho romano I. Historia y fuentes del derecho romano, Universidad de La Habana, La Habana, 1946.

Chávez Ascencio, Manuel F., La familia en el derecho. Derecho de familia y relaciones jurídicas familiares, Porrúa, México, 2000.

Congreso Internacional de Derecho de Familia XIII "Perspectivas del derecho de familia en el siglo xxı", Resúmenes, Sevilla y Huelva, 18-22 de octubre del 2004.

Díez Picazo, Luis y Gullón, Antonio, Sistema de derecho civil, Tecnos, Madrid, 1988.

Enciclopedia jurídica española, t. I, Francisco Seix Editor, Barcelona, 1910.

Esquivias Jaramillo, José Ignacio, Adopción internacional, Editorial Colex, Madrid, 1998.

Fernández Guerra, Irma Renee, Consideraciones sobre la adopción extraterritorial de niños cubanos, La Habana.

Garcés Cisnero, José, "La adopción”, en Revista Cubana de Derecho, 34, julioseptiembre de 1988, pp. 75-121.

Gisbert Job, Teresa, Ley de Protección Jurídica del Menor. Comunidad valenciana. Ley Orgánica 1/1996 del 15 de enero.

Gómez Treto, Raúl, "La adopción de hijos en el derecho histórico, comparado, internacional y cubano y la protección a la niñez y la juventud", en Revista Cubana de Derecho, 3, abril-junio de 1984.

Hodgking, Rachel y Newel, Peter, Manual sobre la Convención de los Derechos del Niño, preparado para la Unicef, Editorial Atar Roto, Ginebra, 2001.

Iglesias Redondo, Julio Ignacio, Guarda asistencial, tutela exlege y acogimiento de menores, Cedecs Editorial, Barcelona, 1996.

Manresa Navarro, José María, Comentarios al Código Civil español. t. I, Imprenta de la Revista de la Legislación, Madrid, 1907.

Mansilla y Mejía, María Elena, "La Convención Interamericana sobre Tráfico Internacional de Menores", Revista de Derecho Privado, 16, México, eneroabril de 1995.

Memorias del VIII Congreso Mundial sobre Derecho de Familia, t. I, Caracas, 1994.

Mesa Castillo, Olga, Módulos de derecho de familia, Editorial Félix Vare, La Habana, 1999.

Parra Aranguren, Gonzalo, “La Convención de La Haya de 1993 sobre la protec- 
ción del niño y la cooperación en materia de adopción internacional”, Boletín de la Facultad de Derecho, 6, Madrid, verano-otoño de 1994.

Peral Collado, Daniel A., Derecho de familia, La Editorial Pueblo y Educación, La Habana, 1980.

Ramos Chaparro, Enrique, Ciudadanía y familia. Los estados civiles de la persona, Cedecs Editorial, Barcelona, 1999.

Sánchez de Bustamante y Sirven, Antonio, Derecho internacional privado, t. I, Editora Canasa, La Habana, 1931.

Siqueiros, José, "La convención relativa a la protección de menores y a la cooperación en materia de adopción internacional”, en Jurídica, 23, México, 1994.

\section{Documentos}

- Declaración Universal de los Derechos del Niño, de 20 de noviembre de 1959.

- Convención sobre los Derechos del Niño, de 20 de noviembre de 1989.

- Convenio de La Haya relativo a la protección y a la cooperación en materia de adopción internacional, de 29 de mayo de 1993.

- Declaración Universal de los Derechos Humanos, de 10 de diciembre de 1948.

- Legislación del menor, Biblioteca de Textos Legales, Tecnos, Madrid, 1999. 